\title{
EPSL
}

ELSEVIER

\section{Oxygen isotope evidence regarding the formation of spinel-bearing chondrules}

\author{
Seiji Maruyama ${ }^{\mathrm{a}, *}$, Hisayoshi Yurimoto ${ }^{\mathrm{b}}$, Shigeho Sueno ${ }^{\mathrm{c}}$ \\ ${ }^{a}$ Venture Business Laboratory, University of Tsukuba, Tsukuba, Ibaraki 305-8573, Japan \\ ${ }^{b}$ LPS, Earth and Planetary Sciences, Tokyo Institute of Technology, Meguro, Tokyo 152-8551, Japan \\ ${ }^{c}$ Institute of Geoscience, University of Tsukuba, Tsukuba, Ibaraki 305-8571, Japan
}

Received 2 November 1998; revised version received 9 March 1999; accepted 11 March 1999

\begin{abstract}
Oxygen isotope compositions of individual mineral grains in two spinel-bearing chondrules have been determined by secondary ion mass spectrometry. $\mathrm{O}$ isotope ratios of spinel grains in a plagioclase-rich chondrule were extremely ${ }^{16} \mathrm{O}$-rich $\left(\delta^{18} \mathrm{O} \sim \delta^{17} \mathrm{O} \sim-35 \%\right.$ ) indicating close relationship to spinels in $\mathrm{Ca}-\mathrm{Al}$-rich inclusions (CAIs), whereas $\mathrm{O}$ isotope ratios of a spinel grain in barred-olivine chondrule were less enriched in ${ }^{16} \mathrm{O}\left(\delta^{18} \mathrm{O} \sim \delta^{17} \mathrm{O} \sim-10 \%\right)$. The degree of ${ }^{16} \mathrm{O}$-excesses among minerals within each chondrule was parallel to the crystallization sequences. These measurements suggest that some CAI-spinel grains were incorporated into the chondrule precursors, and that the $\mathrm{O}$ isotopic variation among minerals may result in incomplete exchange of $\mathrm{O}$ isotopes between ${ }^{16} \mathrm{O}$-rich chondrule melt and ${ }^{16} \mathrm{O}$-poor ambient nebular gas. The mesostasis having an O-isotopic composition near the terrestrial fractionation line may have been somewhat affected by the aqueous alteration in the parent body. (C) 1999 Elsevier Science B.V. All rights reserved.
\end{abstract}

Keywords: meteorites; chondrules; calcium-aluminium inclusions; spinel group; oxygen; isotopes; secondary ion mass spectroscopy

\section{Introduction}

Chondrule- and CAI-forming events are widely believed to have occurred in the solar nebula although relations among them are poorly understood [1]. CAIs have larger ${ }^{16} \mathrm{O}$-excesses and larger quantities of short-lived nuclides such as ${ }^{26} \mathrm{Al}$ than chondrules [2,3]. This evidence favors the view that chondrules and CAIs might be formed by different processes, at times [2] and/or places far removed from one another $[1,4]$.

\footnotetext{
* Corresponding author. Fax: +81 298536001

E-mail: maruyama@arsia.geo.tsukuba.ac.jp
}

In $\mathrm{CV}$ chondrites, the oxygen isotope ratios of chondrules are quite different from those of CAIs; the ${ }^{16} \mathrm{O}$-rich component is extremely enriched in CAIs, whereas less enriched in chondrules [3]. One of the ${ }^{16} \mathrm{O}$-rich end-members among CAI minerals is spinel which shows $\sim 4 \%$ enrichment of ${ }^{16} \mathrm{O}$ relative to the standard mean ocean water (SMOW). Therefore, $\mathrm{O}$ isotope compositions offer good tracers for discussing relationships between chondrules and CAIs. Especially, O isotopes of rare of spinel grains in chondrules may provide key evidence $[2,5,6]$. However, it is unclear whether CAI-like spinels observed in chondrules are genetically related to CAIspinels. We made in-situ $\mathrm{O}$ isotope measurements of individual mineral grains within two spinel-bearing 
chondrules (A1-2b-1 and AL95-2-1-CDL.1) from the Allende CV carbonaceous chondrite.

\section{Experimental procedure}

Back-scattered electron imaging and quantitative analyses were performed on the JEOL JSM-5400 scanning electron microscope (SEM) equipped with the Oxford LINK energy dispersive system (EDS). In each mineral phase, the concentrations of major elements were determined using the EDS. The quantitative analyses were carried out at an accelerating voltage of $20 \mathrm{kV}$ with $0.3 \mathrm{nA}$ probe current with counting times of $50 \mathrm{~s}$. Conventional ZAF methods were used to convert X-ray intensity to concentration.

Oxygen isotopic measurements were performed with the TiTech Cameca ims 1270 SIMS instrument using a $\sim 5 \mu \mathrm{m}$ diameter $\mathrm{Cs}^{+}$beam and an electron flood gun to compensate for electrostatic charging on Au-coated sample surface. The mass resolution power was set to $\sim 6000$ to resolve ${ }^{17} \mathrm{O}$ from the interference of ${ }^{16} \mathrm{OH}$. Measurements were made by magnetic peak jumping through the following mass sequences; the tail of ${ }^{16} \mathrm{O}^{-},{ }^{16} \mathrm{O}^{-},{ }^{17} \mathrm{O}^{-},{ }^{16} \mathrm{OH}^{-}$, and ${ }^{18} \mathrm{O}^{-}$. Measurements of the tail of ${ }^{16} \mathrm{O}$ and ${ }^{16} \mathrm{OH}$ were performed for correction of the ${ }^{16} \mathrm{OH}$ contribution on ${ }^{17} \mathrm{O}$ peaks. This correction is always less than $0.5 \%$. Secondary ion signals were detected with an electron multiplier. Data were corrected for deadtime $(21.2 \pm 0.8 \mathrm{~ns})$ and the instrumental mass fractionation by utilizing a terrestrial spinel standard [7]:

$$
\begin{aligned}
\delta^{17 \text { or }{ }^{18}} \mathrm{O}_{\text {SMOW }}= & \left(\frac{{ }^{17 \text { or }}{ }^{18} \mathrm{O} /{ }^{16} \mathrm{O}_{\text {sample }}}{17 \text { or }{ }^{18} \mathrm{O} /{ }^{16} \mathrm{O}_{\text {SMOW }}}-1\right) \\
& \times 1000[\% \text { o }]
\end{aligned}
$$

where SMOW indicates standard mean ocean water value.

The critical parameter to be determined from the $\mathrm{O}$ isotope measurements is the magnitude of deviation of the data points from a reference line, taken as the fractionation line for the terrestrial materials. The terrestrial fractionation (TF) line is defined as: $\delta^{17} \mathrm{O}=0.52 \delta^{18} \mathrm{O}$. For chondrules, an excess in ${ }^{17} \mathrm{O}$ can be defined as follows: $\Delta^{17} \mathrm{O}=\delta^{17} \mathrm{O}-0.52 \delta^{18} \mathrm{O}$. The magnitude of the ${ }^{16} \mathrm{O}$-excess of chondrule minerals can be simply shown by the $\Delta^{17} \mathrm{O}$ values.

\section{Results and discussion}

The spinel-bearing chondrule, A1-2b-1 (abbreviated to A1 hereafter), is a low-FeO type-I barredolivine chondrule (BOC) surrounded a porphyritic olivine rim (Fig. 1). A coarse, subhedral spinel grain is embedded in the A1. The composition of the core of the spinel grain is the almost pure $\mathrm{MgAl}_{2} \mathrm{O}_{4}$, whereas the rim is rich in $\mathrm{FeO}(\sim 7.4 \mathrm{wt} \%, 4-60$ $\mu \mathrm{m}$ width) and $\mathrm{Cr}_{2} \mathrm{O}_{3}(\sim 3.2 \mathrm{wt} \%, \sim 30 \mu \mathrm{m}$ width). These chemical compositions and petrography of the A1 resemble those of another Allende chondrule, the $\mathrm{R}-11$ BOC [5], except that the spinel in A1 is not associated with platinum-group metal nuggets but with Ni-rich Fe metal nuggets.

The another spinel-bearing chondrule, AL95-21-CDL.1 (abbreviated to CDL hereafter), can be classified as an independent (members of a set having significantly different textures and/or compositions [8]) and a consorting (one subequal to the other in size and shape [8]) compound chondrule (Fig. 2). The chondrule consists of two (left and right) spheroidal chondrules. Several spinel grains of pure $\mathrm{MgAl}_{2} \mathrm{O}_{4}$ have been observed in the right-hand chondrule of Fig. 2, which can be categorized as a plagioclase-rich chondrule, or a plagioclase-olivine inclusion (POI) of [6]. Olivine and spinel grains in the plagioclase-rich chondrule are poikilitically enclosed by an anorthite-rich assemblage. The spinel grains exhibit a corroded or serrated surface. According to its texture and the chemical composition determined by a broad beam technique of electron microprobe, this plagioclase-rich chondrule may be categorized in the group-2 of [6]. However, in crystallization experiments, the group- 2 melt does not coexist with spinel in equilibrium [6]. These features suggest that the spinel grains observed are a relict phase. No spinel grains have been observed in the left-hand chondrule which consists of a porphyritic olivine chondrule (POC) core enveloped by porphyritic pyroxene chondrule (PPC).

The $\mathrm{O}$ isotopic compositions are shown in Fig. 3, and the oxygen isotopic data of $\mathrm{A} 1$ and $\mathrm{CDL}$ are listed in Table 1 and Table 2, respectively. In the spinel grain in $\mathrm{A} 1$ the $\mathrm{O}$ isotopic composition enriched in ${ }^{16} \mathrm{O}\left(\Delta^{17} \mathrm{O} \approx-8 \%\right.$ ), close to the coexisting barred-olivine $\left(\Delta^{17} \mathrm{O} \approx-6 \%\right.$ ). Because the spinel and the olivine grains have similar $\mathrm{O}$ isotopic 


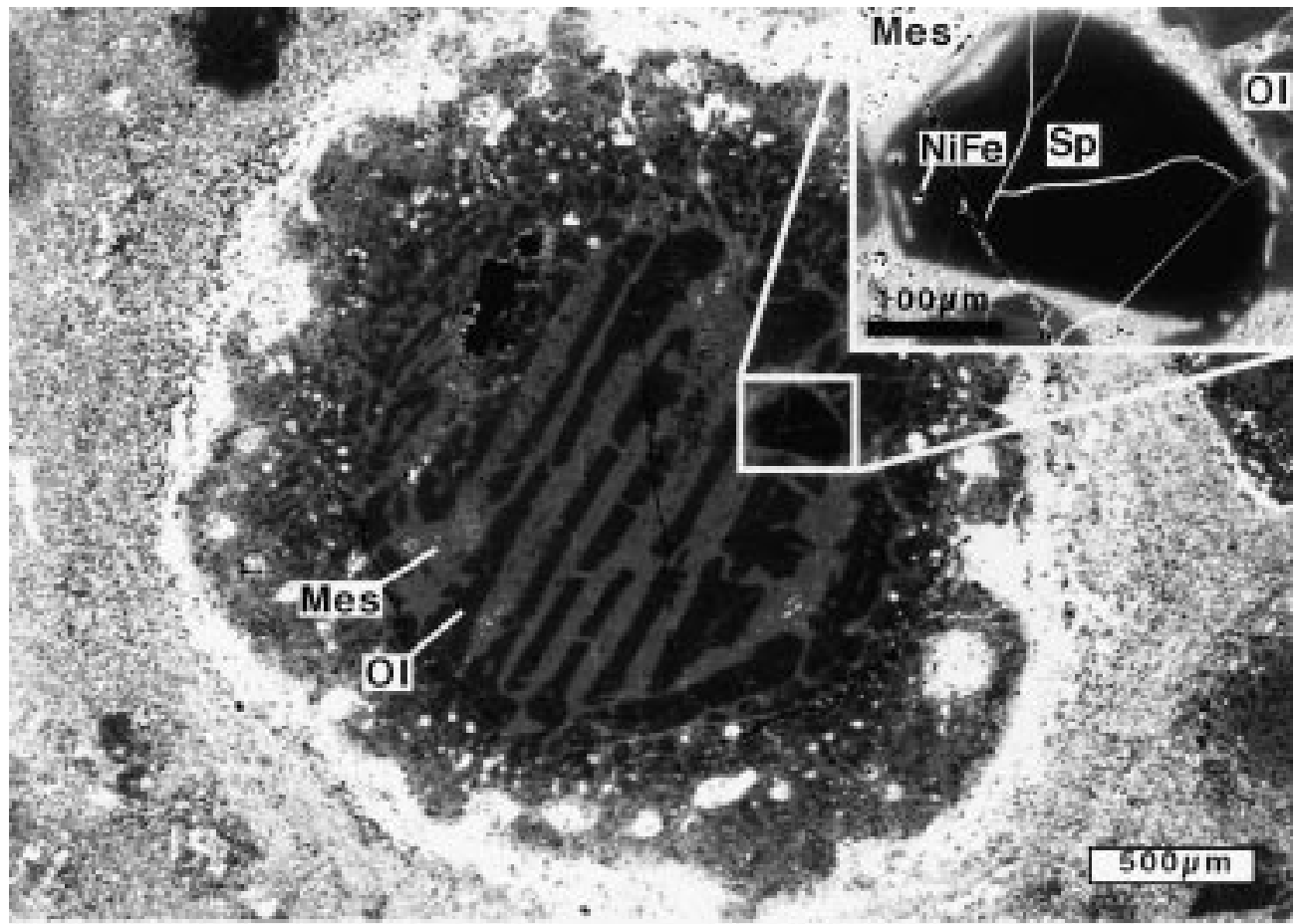

Fig. 1. Back-scattered electron (BSE) image of A1-2b-1 barred-olivine chondrule in the Allende chondrite. This chondrule mainly consists of olivine, mesostasis, spherules of Fe-Ni metal or sulfide. The core part $(\sim 1.7 \mathrm{~mm}$ diameter $)$ is surrounded by the porphyritic olivine rim (200-500 $\mu \mathrm{m}$ width). Olivine bars in the core part are forsteritic (Fo98-100). The mesostasis is dominated by a Ca-feldspathic phase; the fassaitic phase and $\mathrm{Ca}-\mathrm{Fe}$-rich silicate assemblages are surrounded by the feldspathic phase. A coarse subhedral spinel grain is embedded in the core part. Sp: spinel, Ol: olivine, Mes: mesostasis, NiFe: Ni-Fe metal nugget.

compositions, we conclude that the spinel grain was a primary phase during the chondrule crystallization; its subhedral texture of spinel supports the in-situ crystallization. Similar ${ }^{16} \mathrm{O}$-excesses have been observed in individual olivine grains $[9,10]$ and in olivine grains of a POC [11] from the Allende meteorite. This evidence suggests that the spinel grain in A1 is not related to CAI spinels in spite of the similarity of chemical composition.

The spinel grains in CDL showed extreme $\mathrm{O}$ isotopic composition enriched in ${ }^{16} \mathrm{O}\left(\Delta^{17} \mathrm{O} \approx-17 \%\right)$, close to the CAI spinel value $(\approx-20 \%$ o). Such a large ${ }^{16} \mathrm{O}$-excess has not previously been observed in chondrules. Similarities of the ${ }^{16} \mathrm{O}$-excess and of the chemical composition demonstrate that the origin of this spinel grain is linked to those of the spinel grains in CAIs.

The O isotopic compositions of olivine, pyroxenes, anorthite and nepheline in the plagioclase-rich chondrule are less enriched in ${ }^{16} \mathrm{O}$ than those of spinel grains. All data plot along the carbonaceous chondrite anhydrous minerals (CCAM) line. The range in $\mathrm{O}$ isotopic compositions in this plagioclaserich chondrule is greater than observed in past analyses of individual olivine grains $[9,10]$ and chondrules $[3,11]$. The observed disequilibrium in $\mathrm{O}$ isotopes indicates that the spinel grains are relict phases which have survived the chondrule-forming event [6], and suggest that the spinel grains were related to the CAI forming event.

Laboratory studies of the group- 2 melt show that olivine is the first phase to crystallize, followed by pyroxenes and anorthite [6]. Nepheline exists as matrix surrounding other phases or partially replacements of anorthite grains. From the textural observation, nepheline is apparently the secondary phase as a result of the alteration of anorthite. Similar occurrence of nepheline in Allende chondrules has been observed by [12]. The crystallization sequence is parallel to the degree of ${ }^{16} \mathrm{O}$-enrichment we observed 


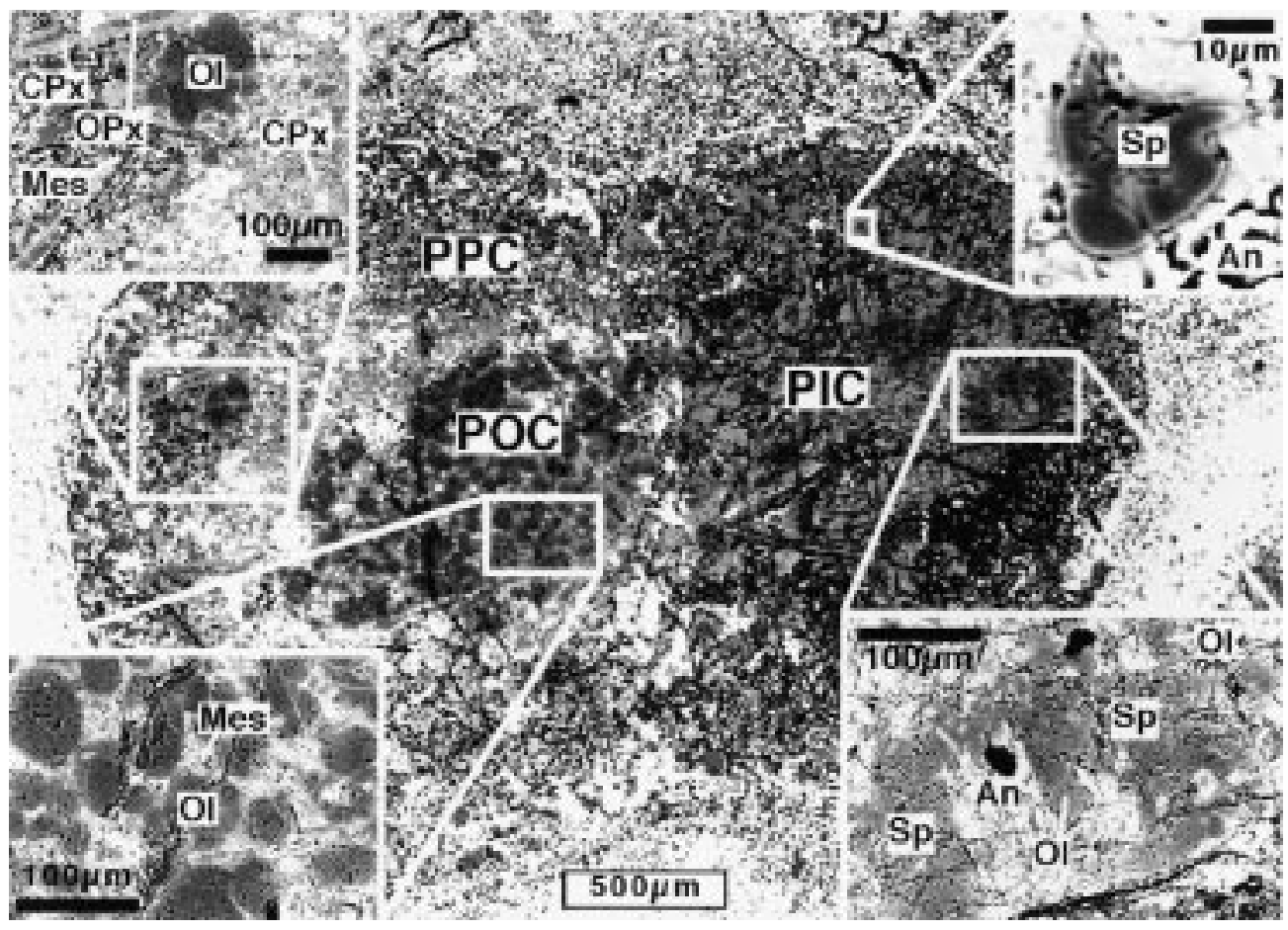

Fig. 2. Back-scattered electron (BSE) image of AL95-2-1-CDL.1 compound chondrule from the Allende chondrite. The porphyritic olivine chondrule $(P O C)$ mainly consists of porphyritic olivine grains (Fo98) and interstitial mesostasis. The enveloping porphyritic pyroxene chondrule $(P P C)$ consists of abundant Ca-rich pyroxene lath and porphyritic Ca-poor pyroxene. Olivine (Fo ${ }_{85}$ ) is minor phase. The interstitial mesostasis bears $\mathrm{Na}$ and $\mathrm{Cl}$. The plagioclase-rich chondrule $(P l C)$ has a sub-ophitic texture and consists of Ca-rich pyroxene (small Ca-poor pyroxene cores exist), anorthite $\left(\mathrm{An}_{88-100}\right)$, olivine (Fo90-98), spinel and nepheline. Sp: spinel, An: anorthite, Ol: olivine, $O P x$ : Ca-poor pyroxene, $C P x$ : Ca-rich pyroxene, Mes: mesostasis.

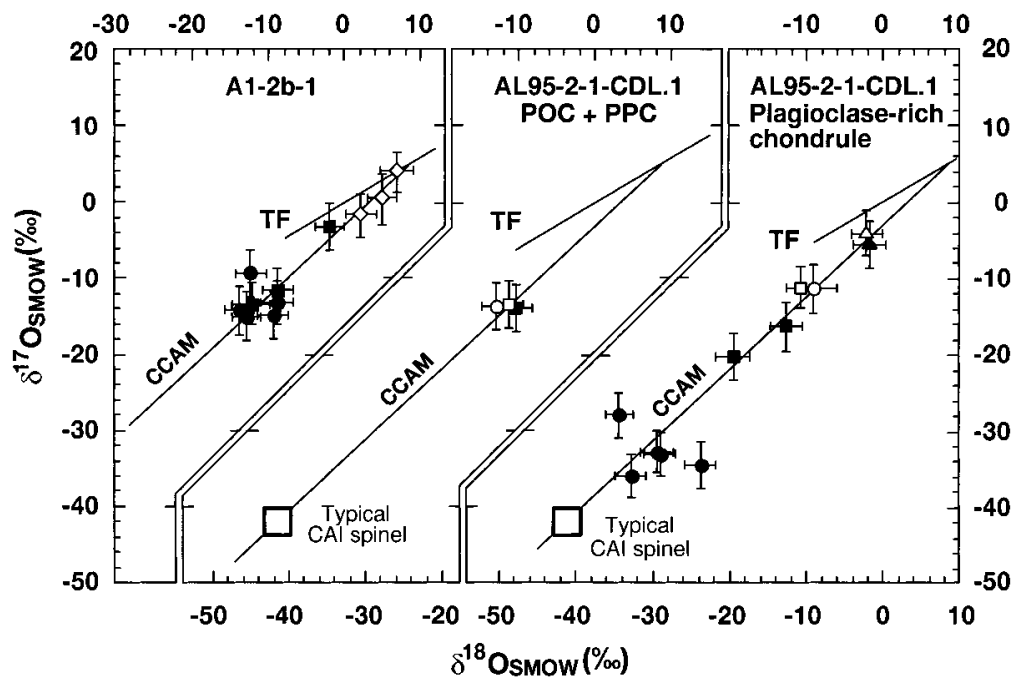

Fig. 3. Oxygen isotopic compositions of each phase in the AL95-2-1-CDL.1 and the A1-2b-1 chondrules. All errors are $1 \sigma$ mean. Typical CAI spinel value [3] is also plotted. $T F$ : terrestrial fractionation line [3], CCAM: carbonaceous chondrite anhydrous minerals line [3]. Solid circle: spinel, solid square: olivine, open circle: Ca-rich pyroxene, open square: Ca-poor pyroxene, solid triangle: anorthite, open triangle: nepheline, open diamond: mesostasis. 
Table 1

Oxygen isotopic data for Allende barred-olivine chondrule A1-2b-1

\begin{tabular}{|c|c|c|c|c|c|}
\hline Analysis & $\begin{array}{l}\delta^{17} \mathrm{O}_{\mathrm{SMOW}} \\
(\% \circ)\end{array}$ & $\sigma_{\text {mean }}$ & $\begin{array}{l}\delta^{18} \mathrm{O}_{\text {SMOW }} \\
(\% \circ)\end{array}$ & $\sigma_{\text {mean }}$ & $\begin{array}{l}\Delta^{17} \mathrm{O} \\
(\% o)\end{array}$ \\
\hline \multicolumn{6}{|l|}{ Spinel } \\
\hline $\mathrm{SpC01}$ & -13.2 & 2.8 & -8.3 & 2.1 & -8.9 \\
\hline $\mathrm{SpC02}$ & -14.2 & 3.2 & -13.2 & 2.0 & -7.3 \\
\hline $\mathrm{SpC03}$ & -15.0 & 3.1 & -12.3 & 1.9 & -8.6 \\
\hline SpR01 & -9.4 & 3.0 & -11.7 & 2.0 & -3.3 \\
\hline SpR05 & -14.9 & 3.0 & -8.8 & 2.0 & -10.3 \\
\hline Average $^{a}$ & -13.3 & 1.0 & -10.8 & 1.0 & -7.7 \\
\hline \multicolumn{6}{|l|}{ Olivine } \\
\hline $\mathrm{O} 106\left(\mathrm{Fo}_{100}\right)^{\mathrm{b}}$ & -3.2 & 3.2 & -1.3 & 1.8 & -2.5 \\
\hline Ol10(Fo99) & -11.5 & 2.9 & -8.1 & 2.1 & -7.3 \\
\hline $\mathrm{Ol11}\left(\mathrm{Fo}_{100}\right)$ & -13.3 & 2.7 & -11.6 & 2.5 & -7.3 \\
\hline Average $^{a}$ & -9.4 & 3.1 & -7.0 & 3.0 & -5.7 \\
\hline \multicolumn{6}{|l|}{ Mesostasis } \\
\hline Meso01 & -1.7 & 2.8 & 2.8 & 2.0 & -3.2 \\
\hline Meso02 & 0.4 & 3.3 & 5.6 & 1.9 & -2.5 \\
\hline Meso06 & 4.0 & 2.6 & 7.5 & 2.0 & 0.1 \\
\hline Average $^{a}$ & 0.9 & 1.7 & 5.3 & 1.3 & -1.9 \\
\hline
\end{tabular}

Standard errors $\left(\sigma_{\text {mean }}\right)$ were calculated from standard deviation of a measurement cycle and the cycle numbers.

a Average of each mineral and the standard error of the mean were calculated from the values of each spot.

${ }^{\mathrm{b}}$ Forsteritic content.

among minerals of the plagioclase-rich chondrule, i.e., olivine is the most ${ }^{16} \mathrm{O}$-enriched phase $\left(\Delta^{17} \mathrm{O} \approx\right.$ $-10 \%$ o among the silicate phases, whereas anorthite or nepheline is the least ${ }^{16} \mathrm{O}$-enriched phase $\left(\Delta^{17} \mathrm{O}\right.$ $\approx-5 \%$ ).

The similar relationship of $\mathrm{O}$ isotope ratio among minerals is also observed in A1, i.e., minerals which crystallized early, such as spinel, are more enriched in ${ }^{16} \mathrm{O}$ than mesostasis. The $\Delta^{17} \mathrm{O}$ values of olivine grains in $\mathrm{A} 1$ varies from $\sim-7 \%$ o (the spinel value) to $\sim-3 \%$ o (near the mesostasis value). The $\mathrm{O}$ isotopic compositions of mesostasis in A1 show the values near the TF line. The values of mesostasis may not preserve the $\mathrm{O}$ isotope ratio of chondrule melt at solidification, but result from $\mathrm{O}$ isotopic exchange during aqueous alteration in the parent body because the Allende meteorite shows evidence of the aqueous alteration $[13,14]$.

The evidence among primary minerals in the chondrules implies that the chondrule melt droplets were originally enriched in ${ }^{16} \mathrm{O}$, and the degree of
Table 2

Oxygen isotopic data for compound chondrule AL95-2-1-CDL.1

\begin{tabular}{|c|c|c|c|c|c|}
\hline Analysis & $\begin{array}{l}\delta^{17} \mathrm{O}_{\text {SMOW }} \\
(\% \circ)\end{array}$ & $\sigma_{\text {mean }}$ & $\begin{array}{l}\delta^{18} \mathrm{O}_{\text {SMOW }} \\
(\% o)\end{array}$ & $\sigma_{\text {mean }}$ & $\begin{array}{l}\Delta^{17} \mathrm{O} \\
(\% o)\end{array}$ \\
\hline \multicolumn{6}{|c|}{ AL95-2-1-CDL.1 (Plagioclase-rich chondrule) } \\
\hline \multicolumn{6}{|l|}{ Spinel } \\
\hline Sp01 & -33.0 & 2.9 & -28.8 & 2.0 & -18.1 \\
\hline $\mathrm{Sp} 02$ & -35.8 & 2.9 & -32.5 & 2.0 & -18.8 \\
\hline Sp03 & -32.6 & 2.7 & -29.1 & 2.1 & -17.5 \\
\hline Sp04 & -34.3 & 3.1 & -23.6 & 2.0 & -22.0 \\
\hline Sp05 & -27.9 & 3.0 & -34.1 & 1.8 & -10.1 \\
\hline Average $^{a}$ & -32.7 & 1.3 & -29.6 & 1.8 & -17.3 \\
\hline \multicolumn{6}{|l|}{ Olivine } \\
\hline $\mathrm{O} 101\left(\mathrm{Fo}_{97}\right)^{\mathrm{b}}$ & -20.2 & 3.1 & -19.3 & 2.3 & -10.2 \\
\hline Ol02(Fo96) & -16.3 & 3.2 & -12.4 & 2.2 & -9.8 \\
\hline Average $^{a}$ & -18.2 & 2.0 & -15.9 & 3.5 & -10.0 \\
\hline \multicolumn{6}{|c|}{ Ca-rich pyroxene } \\
\hline ssCPx04 & -11.3 & 3.2 & -8.8 & 2.0 & -6.7 \\
\hline \multicolumn{6}{|c|}{ Ca-poor pyroxene } \\
\hline ssOPx01 & -11.2 & 2.7 & -10.4 & 1.9 & -5.8 \\
\hline \multicolumn{6}{|l|}{ Anorthite } \\
\hline An04 & -5.6 & 3.0 & -1.5 & 2.1 & -4.8 \\
\hline \multicolumn{6}{|l|}{ Nepheline } \\
\hline $\mathrm{Ne} 04$ & -4.0 & 3.0 & -2.0 & 2.0 & -3.0 \\
\hline
\end{tabular}

AL95-2-1-CDL.1 (POC-PPC)

Olivine

\begin{tabular}{|c|c|c|c|c|c|}
\hline 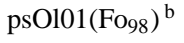 & -14.2 & 3.1 & -10.8 & 2.1 & -8.6 \\
\hline $\begin{array}{l}\text { Ca-rich pyroxer } \\
\text { psCPx01 }\end{array}$ & $\begin{array}{l}e \\
-14.0\end{array}$ & 3.0 & -13.2 & 2.1 & -7.1 \\
\hline $\begin{array}{l}\text { Ca-poor pyroxe } \\
\text { psOPx } 01\end{array}$ & -13.7 & 3.0 & -11.6 & 1.9 & -7.7 \\
\hline
\end{tabular}

Standard errors $\left(\sigma_{\text {mean }}\right)$ were calculated from standard deviation of a measurement cycle and the cycle numbers.

${ }^{a}$ Average of each mineral and the standard error of the mean were calculated from the values of each spot.

${ }^{\mathrm{b}}$ Forsteritic content.

enrichment gradually decreased during the solidification, although $\mathrm{O}$ isotopic composition of mesostasis may have been affected by aqueous alteration in the parent body. The most negative $\Delta^{17} \mathrm{O}$ value of chondrule initial melt that may be reached is $-20 \%$ o according to a recent discovery of extreme ${ }^{16} \mathrm{O}$-rich olivine around a CAI rim [15] and in amoeboid olivine aggregates in a carbonaceous chondrite [16].

Oxygen isotopic exchange reaction between chondrule melt and the surrounding nebular gas, 
in which $\mathrm{O}$ isotopic composition was less enriched in ${ }^{16} \mathrm{O}[3]$, is one mechanism that has been proposed to change the $\mathrm{O}$ isotope ratio of chondrules. This argument is also consistent with the observations between $\mathrm{O}$ isotope ratio of bulk chondrules and the petrographic and chemical features $[17,18]$. Since chondrules may have been formed by pulse heating events and the cooling rate of chondrule melt was in the range of $10-2000^{\circ} \mathrm{C} / \mathrm{hr}[19,20]$, it is necessary to evaluate the degree of the $\mathrm{O}$ isotopic exchange of molten chondrule within a period of hours. As rate-limiting processes for the exchange reaction, $\mathrm{O}$ diffusion rate in the chondrule melt and surface reaction rate of $\mathrm{O}$ isotopic exchange should be considered. If the principal rate-limiting mechanism was diffusion in the melt, homogenization time scale of $\mathrm{O}$ isotope in a molten chondrule, typically $\mathrm{mm}$-size, can be roughly calculated using $\mathrm{O}$ self diffusion [21,22]. The homogenization time scale by diffusion is estimated to the range of several minutes to several hours even at peak temperatures of flash-melted chondrules $\left(1500-1900^{\circ} \mathrm{C}\right)[20,23]$. Therefore, complete equilibrium between chondrule melt and the ambient gas is not obvious during chondrule cooling time scale even if the surface reaction rate was enough fast. Results of oxygen isotope exchange experiments between chondrule composition melt and ambient gas support this argument [24]. Thus, incomplete $\mathrm{O}$ isotopic exchange by nebular gas under rate-limiting processes such as diffusion in melt and/or surface reaction is plausible to explain the variations of $\mathrm{O}$ isotope ratios observed among the minerals within chondrules. The $\mathrm{O}$ isotope ratios observed in chondrules in this study distribute along the CCAM line defined by CAI minerals, indicating that ${ }^{16} \mathrm{O}$-rich dust and ${ }^{16} \mathrm{O}$-poor gas continued together in the solar nebula from the CAI-forming period until the chondrule-forming period.

\section{Conclusion}

The discovery of spinel grains having the $\mathrm{O}$ isotopic composition of both of CAI- and chondrulerelated spinel grains in individual chondrules in the same carbonaceous chondrite indicates that the similarity of chemical composition of major elements is not always sufficient evidence to infer the origin of spinel grains. The existence of the ${ }^{16} \mathrm{O}$-rich spinel provides direct evidence that CAI minerals incorporated into precursor materials of chondrules and some of them survived chondrule-forming events. The variations of $\mathrm{O}$ isotope ratios among silicate minerals in chondrules may indicate that $\mathrm{O}$ isotope exchange reaction has occurred between chondrule melt and the ambient nebular gas, although aqueous alteration in the parent body may have disturbed the $\mathrm{O}$ isotopic composition of mesostasis.

\section{Acknowledgements}

We thank G.L. Kim for technical assistance with the SIMS analyses. We thank J.T. Wasson and an anonymous reviewer for constructive comments and for English correction. Supported by Kagakugijutsu-cho and Monbu-sho grants. [CL]

\section{References}

[1] J.A. Wood, Unsolved issues in the formation of chondrules and chondrites, in: R.H. Hewins, R.H. Jones, E.R.D. Scott (Eds.), Chondrules and the Protoplanetary Disk, Cambridge Univ. Press, Cambridge, UK, 1996, pp. 55-69.

[2] S.S. Russell, G. Srinivasan, G.R. Huss, G.J. Wasserburg, G.J. MacPherson, Evidence for widespread ${ }^{26} \mathrm{Al}$ in the solar nebula and constraints for nebula time scales, Science 273 (1994) 757-762.

[3] R.N. Clayton, Oxygen isotopes in meteorites, Annu. Rev. Earth Planet. Sci. 21 (1993) 115-149.

[4] J.A. Wood, Processing of chondritic and planetary material in spiral density waves in the nebula, Meteoritics Planet. Sci. 31 (1996) 641-645.

[5] K. Misawa, T. Fujita, A relict refractory inclusion in a ferromagnesian chondrule from the Allende meteorite, Nature 368 (1994) 723-726.

[6] Y.J. Sheng, I.D. Hutcheon, G.J. Wasserburg, Origin of plagioclase-olivine inclusions in carbonaceous chondrules, Geochim. Cosmochim. Acta. 55 (1991) 581-599.

[7] H. Yurimoto, H. Nagasawa, Y. Mori, O. Matsubaya, Microdistribution of oxygen isotopes in refractory inclusion from the Allende meteorite, Earth Planet. Sci. Lett. 128 (1994) 47-53.

[8] J.T. Wasson, A.N. Krot, M.S. Lee, A.E. Rubin, Compound chondrules, Geochim. Cosmochim. Acta. 59 (1995) 18471869.

[9] R.L. Hervig, I.M. Steele, Oxygen isotopic analysis of Allende olivine by ion microprobe and implications for chondrule origin, Proc. Lunar Planet. Sci. Conf. 17 (1992) 364365 . 
[10] S. Weinbruch, E.K. Zinner, A. ElGoresy, I.M. Steele, H. Palme, Oxygen isotopic composition of individual olivine grains from the Allende meteorite, Geochim. Cosmochim. Acta. 57 (1993) 2649-2661.

[11] $\mathrm{H}$. Hiyagon, In situ analysis of oxygen isotopes and $\mathrm{Fe} / \mathrm{Mg}$ ratios in olivine using SIMS: preliminary results for an Allende chondrule, Antarct. Meteorite Res. 10 (1997) 249274.

[12] Y. Ikeda, M. Kimura, Anhydrous alteration of Allende chondrules in the solar nebula I: Description and alteration of chondrules with known oxygen-isotopic compositions, Proc. NIPR Symp. Antarct. Meteorites 8 (1995) 97-122.

[13] A.N. Krot, E.R.D. Scott, M.E. Zolensky, Mineralogical and chemical modification of components in CV3 chondrites: Nebular or asteroidal processing?, Meteoritics 30 (1995) $748-775$.

[14] B.-G. Choi, K.D. Mckeegan, L.A. Leshin, J.T. Wasson, Origin of magnetite in oxidized CV chondrites: in situ measurement of oxygen isotope compositions of Allende magnetite and olivine, Earth Planet. Sci. Lett. 146 (1997) 337-349.

[15] H. Hiyagon, Distribution of oxygen isotopes in and around some refractory inclusions from Allende, Lunar Planet. Sci. 29 (1998) abstract 1582.

[16] H. Hiyagon, A. Hashimoto, An ion microprobe study of oxygen isotopes in Yamato-86009 (CV3) chondrite: discovery of ${ }^{16} \mathrm{O}$-rich olivine inclusions, Antarctic Meteorites 23 (1998) 33-35.

[17] R.N. Clayton, N. Onuma, Y. Ikeda, T.K. Mayeda, I.D. Hutcheon, E.J. Olsen, C. Molini-Velsko, Oxygen isotopic compositions of chondrules in Allende and ordinary chondrites, in: E.A. King (Ed.), Chondrules and their Origins, Lunar Planet. Inst., 1983, pp. 37-43.

[18] H.Y. McSween et al., Constraints on chondrule origin from petrology of isotopically characterized chondrules in the Allende meteorite, Meteoritics 20 (1985) 523-540.

[19] R.H. Hewins, Experimental studies of chondrules, in: J.F. Kerridge, M.S. Matthews Eds., Meteorites and the Early Solar System, Univ. of Arizona Press, Tucson, 1988, pp. 660-679.

[20] G.E. Lofgren, A dynamic crystallization model for chondrule melts in chondrules and the protoplanetary disk, in: R.H. Hewins, R.H. Jones, E.R.D. Scott (Eds.), Chondrules and the Protoplanetary Disk, Cambridge Univ. Press, Cambridge, UK, 1996, pp. 187-196.

[21] J. Crank, The Mathematics of Diffusion, 2nd ed., Oxford Univ. Press, Oxford, 1975.

[22] C.E. Lesher, R.L. Hervig, D. Tinker, Self diffusion of network formers (silicon and oxygen) in naturally occurring basaltic liquid, Geochim. Cosmochim. Acta. 60 (1996) 405-413.

[23] R.H. Hewins, H.C. Connolly, Peak temperatures of flashmelted chondrules, in: R.H. Hewins, R.H. Jones, E.R.D. Scott (Eds.), Chondrules and the Protoplanetary Disk, Cambridge Univ. Press, Cambridge, UK, 1996, pp. 197-204.

[24] Y. Yu, R.H. Hewins, R.N. Clayton, T.K. Mayeda, Experimental study of high temperature oxygen isotope exchange during chondrule formation, Geochim. Cosmochim. Acta. 59 (1995) 2095-2104. 